\title{
Is there a limit to how far we should push the envelope in pediatric cardiac surgery?
}

\author{
Bahaaldin Alsoufi, MD
}

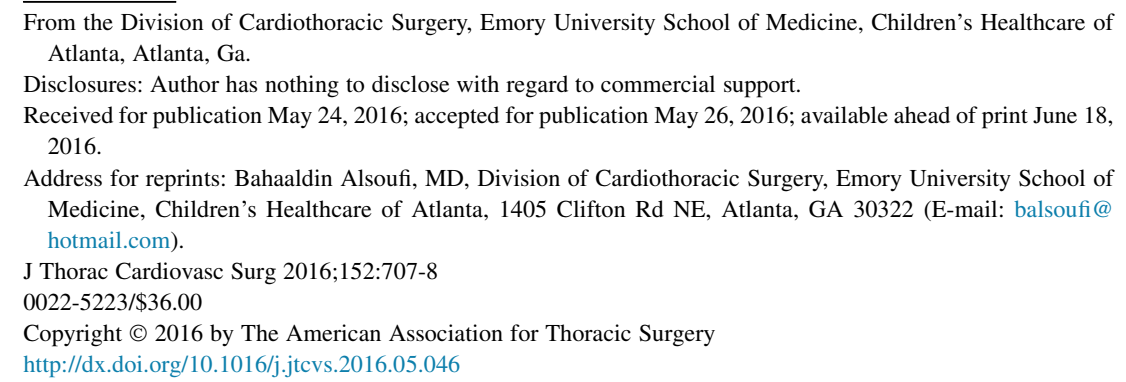

In this issue of the Journal, Villemain and colleagues ${ }^{1}$ describe their extensive experience with surgical repair of double-outlet right ventricle (DORV) in 433 patients over a 21-year period. The authors examine risk factors associated with hospital mortality, late survival, and need for reoperation. They use a comprehensive dataset that includes patient and anatomic characteristics, along with surgical details, to analyze variables affecting outcomes. In their report, survival was $88 \%$ at 1 year and $86 \%$ at 10 years, indicating a high early mortality risk that peaks in the perioperative period and persists during the first year after surgery. In addition, freedom from cardiac reoperation was $61 \%$ at 10 years.

Despite the authors' large patient cohort, analysis of the entire group of patients as a whole is of limited value, owing to the heterogeneous nature of this patient population and the different surgical approaches used to treat DORV and associated cardiac anomalies. A more detailed examination of repair outcomes and associated factors in different subgroups of interest is likely to be more fruitful and informative.

One particular group of interest included 23 patients with DORV and noncommitted ventricular septal defect (VSD) who underwent biventricular repair. Operative mortality was the highest in this anatomic subtype, approaching $25 \%$, and freedom from cardiac reoperation was the lowest, approaching $40 \%$ at 10 years, with only 1 patient alive and free from reoperation at 10 years after biventricular repair. Those results are disappointing and compare unfavorably to current single ventricle palliation outcomes with the Fontan operation. ${ }^{2,3}$ In patients requiring a very involved biventricular repair of complicated cardiac anomalies, such as DORV with noncommitted VSD, complex corrected transposition of the great arteries, or atrial isomerism with multiple associated intracardiac lesions, the following question remains to be answered: Is it preferable to perform a high-risk biventricular repair associated with high mortality and the need for reoperation,

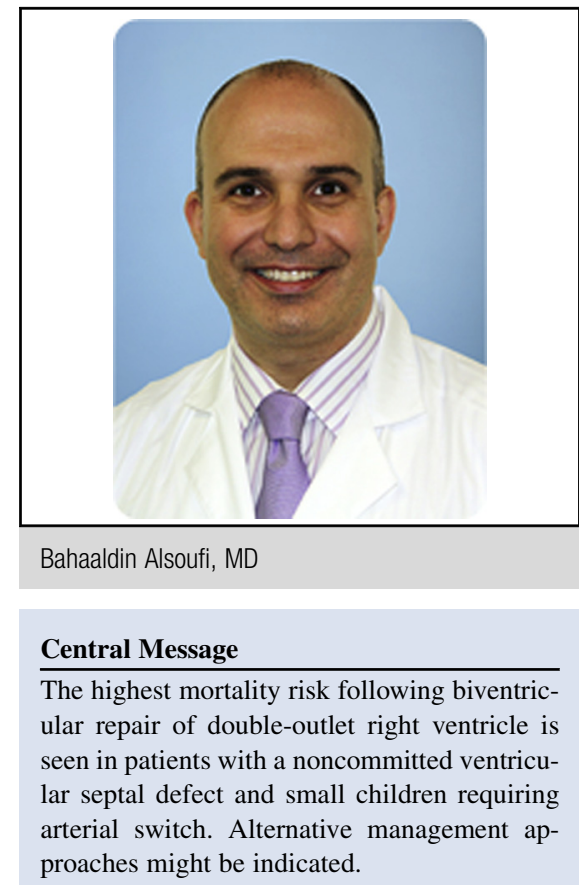

See Article page 698

or is it preferable to perform a low-risk single ventricle palliation associated with a low need for reoperation and might be associated with superior survival compared with other single ventricle anomalies? $?^{4}$ This question continues to perplex cardiologists and surgeons, and the answer remains elusive.

Villemain and colleagues ${ }^{1}$ have accumulated extensive experience with biventricular repair of complex DORV, and the results they present are alarming and suggest the need for extreme thoughtfulness when evaluating whether to offer complex biventricular repair to patients with DORV and noncommitted VSD. Other groups who used a single ventricle palliation strategy in similar patients with complex DORV have reported superior operative mortality, late survival, and freedom from cardiac reoperation compared with those reported with biventricular repair in the current report. ${ }^{5}$ Although late complications after the Fontan procedure are well known and not negligible, ${ }^{6}$ based on this report, the appropriate solution to improve outcomes in those patients does not seem to be performing a complex biventricular repair. 
The other subgroup of interest includes patients with Taussig-Bing anomaly, who usually require an arterial switch operation plus an intracardiac baffle. The common association of additional cardiac lesions, such as aortic arch obstruction, atypical coronary anatomy, and right ventricular outflow tract obstruction, make those operations among the longest and most complex procedures performed by congenital cardiac surgeons. ${ }^{7}$ In the current report from Paris, operative mortality occurred in 15 of 121 patients $(12 \%)$ who underwent an arterial switch operation plus intracardiac baffle repair. Analysis of variables associated with death in this subgroup of patients identified such factors as low weight, concomitant cardiac surgery, and the need for early unplanned cardiac reoperation as associated with an increased risk of operative death. The 2 teams in Paris (Necker Enfants Malades and Marie Lanelongue) are leading practitioners of pediatric cardiac surgery in Europe and have published some of the largest series of arterial switch operations to date; in other words, there is no lack of surgical expertise to explain the high operative mortality. On the other hand, increased surgical complexity with concomitant cardiac surgery (most commonly aortic arch repair and right ventricular outflow obstruction relief), particularly in patients of very low weight, is associated with a higher risk of mortality, especially in the presence of residual lesions requiring unplanned cardiac reoperations. Despite improvements in surgical techniques, perfusion strategies, and perioperative care, low weight remains an independent factor associated with poor surgical repair outcomes.

The findings reported by Villemain and colleagues ${ }^{1}$ suggest that delaying a challenging intracardiac repair in very small infants might be advisable. This can be in the form of (1) traditional pulmonary artery banding with or without arch repair, (2) palliative arterial switch with or without arch repair, plus pulmonary artery banding without intracardiac repair, or (3) the evolving strategy of hybrid palliation with ductal stenting and branch pulmonary artery banding. Subsequent complete biventricular repair in older patients might be better tolerated and associated with superior anatomic outcomes. ${ }^{9}$ Surgeons constantly strive to improve the quality of care provided to their patients, and one aspect of that improvement is performing complete early repair and avoiding palliative surgery, which can be associated with an increased risk of mortality and the need for eventual reoperation. Nonetheless, primary complete repair might not be the optimal choice for all patients, especially very small infants who require a complex intracardiac repair, and the approach should be tailored to each individual patient. Outcomes with certain procedures depend on various elements, including expertise and accessible resources. What might be considered an ideal management strategy in one center might not be the ideal strategy in another center. It is the duty of physicians to assess their own results and decide on the safest and most appropriate approach that works for the various groups of patients.

Our field of pediatric cardiac surgery continues to grow, owing to innovations in management strategies, surgical techniques, and medical technology. These advances are credited to pioneer physicians and surgeons who persistently pushed the envelope to improve on treatment approaches that did not work too well. This tradition is definitely needed in our specialty, and investigations of new surgical techniques and inventive technology should be encouraged. It is our obligation to constantly examine and report the results of those innovations and assess whether or not they have achieved their purpose. A conversion to the safer traditional way of doing things should not be viewed as lack of success. Based on the available reports, I believe that staged palliation of very small children who require an extremely complex intracardiac repair is justified in selected cases. Moreover, single ventricle palliation in patients with complex DORV, such as those with a straddling atrioventricular valve and noncommitted VSD, although not perfect, might be the superior management approach.

\section{References}

1. Villemain O, Belli E, Ladouceur N, Houyel L, Jalal Z, Lambert V, et al. Impact of anatomic characteristics and initial biventricular surgical strategy on outcomes in various forms of double-outlet right ventricle. J Thorac Cardiovasc Surg. 2016; 152:698-706.e3.

2. Stamm C, Friehs I, Mayer JE Jr, Zurakowski D, Triedman JK, Moran AM, et al. Long-term results of the lateral tunnel Fontan operation. J Thorac Cardiovasc Surg. 2001;121:28-41.

3. Hirsch JC, Goldberg C, Bove EL, Salehian S, Lee T, Ohye RG, et al. Fontan operation in the current era: a 15-year single institution experience. Ann Surg. 2008;248:402-10.

4. Delius RE, Rademecker MA, de Leval MR, Elliott MJ, Stark J. Is a high-risk biventricular repair always preferable to conversion to a single ventricle repair? J Thorac Cardiovasc Surg. 1996;112:1561-8.

5. Brown JW, Ruzmetov M, Okada Y, Vijay P, Turrentine MW. Surgical results in patients with double outlet right ventricle: a 20-year experience. Ann Thorac Surg. 2001;72:1630-5.

6. Rychik J. The relentless effects of the Fontan paradox. Semin Thorac Cardiovasc Surg Pediatr Card Surg Annu. 2016;19:37-43.

7. Alsoufi B, Cai S, Williams WG, Coles JG, Caldarone CA, Redington AM, et al. Improved results with single-stage total correction of Taussig-Bing anomaly. Eur J Cardiothorac Surg. 2008;33:244-50.

8. Alsoufi B, Manlhiot C, Mahle WT, Kogon B, Border WL, Cuadrado, et al. Low-weight infants are at increased mortality risk after palliative or corrective cardiac surgery. J Thorac Cardiovasc Surg. 2014;148:2508-14.

9. Yerebakan C, Murray J, Valeske K, Thul J, Elmontaser H, Mueller M, et al. Long-term results of biventricular repair after initial Giessen hybrid approach for hypoplastic left heart variants. J Thorac Cardiovasc Surg. 2015;149: 1112-20. 